\title{
Production of humic acids from lignites and subbituminous coals by alkaline-air oxidation
}

\author{
Roberto Juan, Carmen Ruiz, José M. Andrés and Mercedes Estévez \\ Instituto de Carboquímica, C.S.I.C., Pza. Paraíso no. 4, Apdo 589, Zaragoza, Spain \\ (Received 12 June 1989)
}

\begin{abstract}
The alkaline oxidation of four Spanish coals by air was studied using a two-level factorial design with four variables: temperature, time, alkali concentration and coal-to-alkali ratio. The main aim was to increase the humic acid content of these coals. The best results were obtained at the highest temperature, longest time and lowest alkali concentration and coal-to-alkali ratio. Lower rank coals yielded the highest humic acid concentrations after oxidation, while the subbituminous coals were only slightly affected by treatment under the test conditions. A detailed study of the elemental composition of the coal and the generation of oxygen-containing functional groups is reported. The evolution of sulphur forms during the process is also described.
\end{abstract}

(Keywords: lignite; subbituminous coal; oxidation)

The alkaline oxygen oxidation of coal has been investigated by several authors. Most workers attempted to obtain benzene-polycarboxylic acids (BPCA) ${ }^{1-3}$, while others aimed to increase the humic acid content of the coal $^{1}$. They found that alkaline oxidation was a stepped process. The main initial products were alkali-soluble, water-insoluble substances, called regenerated humic acids (RHA), which were susceptible to further oxidative decomposition. If the reaction continued, the whole coal was completely transformed to soluble material with humic acids (HA and RHA) decomposed to BPCA, low molecular weight acids, and carbon dioxide ${ }^{4}$.

Several methods for the production of humic acids or derivatives from coal were studied, including dry air oxidation $^{5,6}$ and nitric acid oxidation ${ }^{7}$. Another method investigated was alkaline oxygen oxidation of coal, and the results of these tests are reported in this paper. The main goal was to study the influence of temperature, time, alkali concentration, coal-to-alkali ratio and coal rank on the production of RHA, which are used as soil conditioners $^{8}$. The choice of variables was made in view of earlier reports on this subject ${ }^{9,10}$. Other variables, such as particle size and air flow, were kept constant. Additional runs were performed in which the oxidizing agent (air) was replaced with an inert gas (nitrogen) to differentiate between extraction and oxidation processes. The oxidized coal samples were examined for modification of the \% RHA, elemental composition and phenolic and carboxyl groups.

\section{EXPERIMENTAL}

The coals used were two lignites from Arenas del Rey (A) and Puentes de García Rodríguez (P), and two subbituminous coals from Estercuel (E) and Berga (B) (Spain). Their proximate and ultimate analyses and their $\%$ HA, have been described previously ${ }^{6}$.

The coal samples were mixed with $100 \mathrm{ml}$ of the corresponding KOII solution in a conical flask, while bubbling the appropriate gas $\left(\mathrm{CO}_{2}\right.$-free air or $\left.\mathrm{N}_{2}\right)$ through the suspension. The complete installation is shown in Figure 1.

Two $2^{4}$ factorial designs were used, each one requiring 16 runs. A series of replicates were carried out in the centre of the plan to calculate the standard error. The design matrix, factor levels and \% $\mathrm{HA}$ and $\% \mathrm{RHA}$ are shown in Table 1 . The \% HA or \% RHA was monitored colorimetrically at $450 \mathrm{~nm}$ in the whole alkaline extract buffered at pH 9. Calibration lines were performed at working temperatures.

Further studies of the products obtained at the best oxidation conditions $\left(80^{\circ} \mathrm{C}, 4 \mathrm{~h}, 0.5 \mathrm{~N} \mathrm{KOH}\right.$ and $1: 20$ (w/v) coal-to-alkali ratio) were carried out by stopping the reaction by adding $5 \mathrm{~N} \mathrm{HCl}$, until the $\mathrm{pH}$ reached 1 . The suspension was filtered and the solid fraction washed with water until $\mathrm{Cl}^{-}$was eliminated, and then dried at $60^{\circ} \mathrm{C}$. The oxidized samples were crushed to a particle size $<0.25 \mathrm{~mm}$.

Elemental analyses $(\mathrm{C}, \mathrm{H}, \mathrm{N})$ were obtained using a LECO CHN-600 elemental analyser, total sulphur was determined using a LECO SC-32, and sulphur forms were determined by ASTM methods (standard D-2492). Oxygen was calculated by difference. Carboxyl groups and total acidity were determined with barium acetate and barium hydroxide respectively, using Schafer's methods $^{11,12}$. Phenolic groups were calculated by difference.

\section{RESULTS AND DISCUSSION}

\section{Factorial design}

The results from the factorial design experiments are shown in Table 1. The values have been fitted to the following equation:

$$
\begin{aligned}
y= & b_{0}+b_{1} X_{1}+b_{2} X_{2}+b_{3} X_{3}+b_{4} X_{4}+b_{12} X_{1} X_{2} \\
& +b_{13} X_{1} X_{3}+b_{14} X_{1} X_{4}+b_{23} X_{2} X_{3}+b_{24} X_{2} X_{4}
\end{aligned}
$$




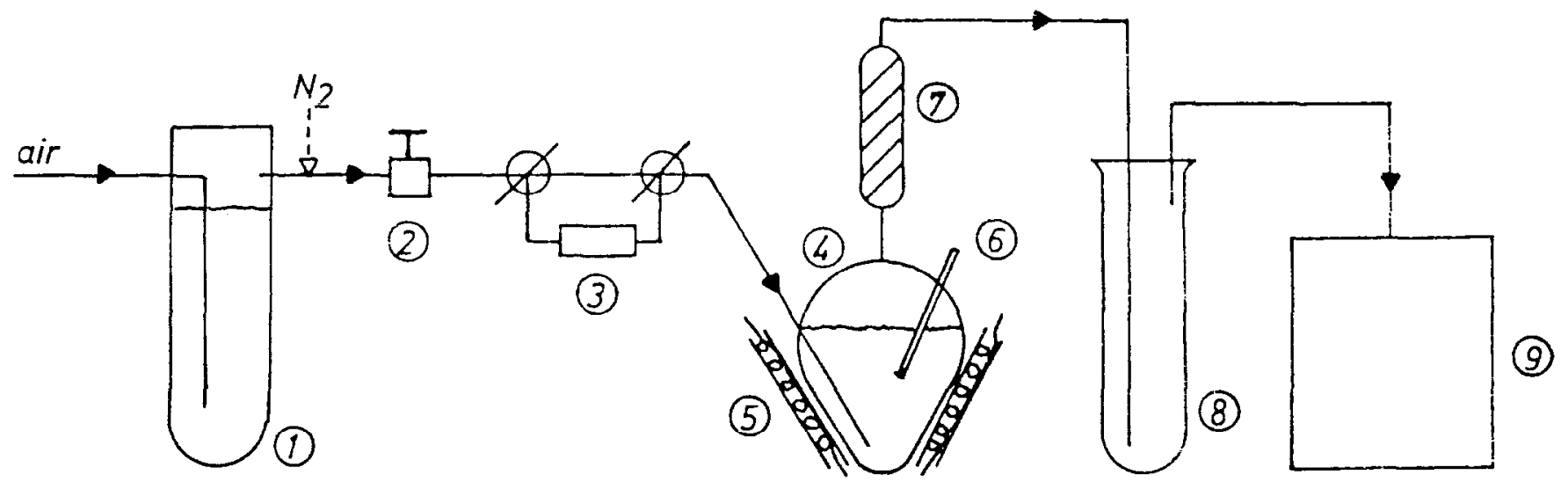

Figure 1 Diagram of the installation used: $1, \mathrm{CO}_{2}$ absorber; 2, flow regulator; 3 , flowmeter; 4, reaction flask; 5, heater; 6, thermometer; 7 , cooler; 8, expansion tube; 9 , vacuum pump

Table 1 Design matrix and results for nitrogen and air processes

\begin{tabular}{|c|c|c|c|c|c|c|c|c|c|c|c|c|c|c|c|c|}
\hline & & & & & & & & & \multicolumn{4}{|c|}{ RHA $(\%)$ in air } & \multicolumn{4}{|c|}{$\mathrm{HA}(\%)$ in $\mathrm{N}_{2}$} \\
\hline \multicolumn{9}{|c|}{ Factorial design ${ }^{a}$} & \multicolumn{4}{|c|}{ Coal } & \multicolumn{4}{|c|}{ Coal } \\
\hline Expt. & $\begin{array}{l}\text { Temp. } \\
\left({ }^{\circ} \mathrm{C}\right)\end{array}$ & $X_{1}$ & $\begin{array}{l}\text { Time } \\
\text { (h) }\end{array}$ & $X_{2}$ & $\begin{array}{l}\text { Conc. } \\
\text { (N) }\end{array}$ & $X_{3}$ & $\begin{array}{l}\text { Ratio } \\
\text { c/a }\end{array}$ & $X_{4}$ & A & $\mathbf{P}$ & $E$ & B & A & $\mathbf{P}$ & E & B \\
\hline 1 & 20 & -1 & 1 & -1 & 0.5 & -1 & $1 / 20$ & -1 & 33.95 & 41.81 & 8.11 & 0.11 & 4.02 & 42.51 & 7.93 & 0.09 \\
\hline 3 & 80 & 1 & 1 & -1 & 0.5 & -1 & $1 / 20$ & -1 & 64.34 & 58.96 & 11.55 & 0.65 & 30.28 & 48.76 & 10.20 & 0.55 \\
\hline 3 & 20 & -1 & 4 & 1 & 0.5 & -1 & $1 / 20$ & -1 & 39.58 & 45.29 & 10.05 & 0.22 & 6.04 & 38.67 & 9.28 & 0.12 \\
\hline 4 & 80 & 1 & 4 & 1 & 0.5 & -1 & $1 / 20$ & -1 & 75.90 & 75.44 & 13.64 & 1.07 & 36.93 & 53.36 & 10.00 & 0.57 \\
\hline 5 & 20 & -1 & 1 & -1 & 1 & 1 & $1 / 20$ & -1 & 30.12 & 32.33 & 6.10 & 0.13 & 4.20 & 30.52 & 6.20 & 0.08 \\
\hline 6 & 80 & 1 & 1 & -1 & 1 & 1 & $1 / 20$ & -1 & 64.34 & 55.17 & 8.89 & 0.67 & 30.51 & 47.43 & 8.23 & 0.57 \\
\hline 7 & 20 & -1 & 4 & 1 & 1 & 1 & $1 / 20$ & -1 & 35.90 & 39.03 & 8.09 & 0.28 & 4.33 & 34.03 & 5.96 & 0.12 \\
\hline 8 & 80 & 1 & 4 & 1 & 1 & 1 & $1 / 20$ & -1 & 71.33 & 66.21 & 11.15 & 1.26 & 35.77 & 52.87 & 8.17 & 0.68 \\
\hline 9 & 20 & -1 & 1 & -1 & 0.5 & -1 & $1 / 10$ & 1 & 33.27 & 41.92 & 8.63 & 0.10 & 4.46 & 40.77 & 8.06 & 0.07 \\
\hline 10 & 80 & 1 & 1 & -1 & 0.5 & -1 & $1 / 10$ & 1 & 51.92 & 56.09 & 9.12 & 0.43 & 36.04 & 49.42 & 8.46 & 0.39 \\
\hline 11 & 20 & -1 & 4 & 1 & 0.5 & -1 & $1 / 10$ & 1 & 40.23 & 48.78 & 9.68 & 0.20 & 6.76 & 44.58 & 8.61 & 0.08 \\
\hline 12 & 80 & 1 & 4 & 1 & 0.5 & -1 & $1 / 10$ & 1 & 56.92 & 60.54 & 10.29 & 0.65 & 39.33 & 49.67 & 8.32 & 0.44 \\
\hline 13 & 20 & -1 & 1 & -1 & 1 & 1 & $1 / 10$ & 1 & 32.14 & 33.62 & 6.06 & 0.11 & 3.36 & 35.39 & 5.80 & 0.07 \\
\hline 14 & 80 & 1 & 1 & -1 & 1 & 1 & $1 / 10$ & 1 & 62.10 & 52.71 & 7.82 & 0.46 & 30.37 & 46.12 & 6.98 & 0.40 \\
\hline 15 & 20 & -1 & 4 & 1 & 1 & 1 & $1 / 10$ & 1 & 38.43 & 38.30 & 7.30 & 0.21 & 4.31 & 37.93 & 6.79 & 0.11 \\
\hline 16 & 80 & 1 & 4 & 1 & 1 & 1 & $1 / 10$ & 1 & 72.09 & 53.12 & 10.34 & 0.75 & 38.45 & 49.09 & 7.39 & 0.53 \\
\hline 17 & 50 & 0 & 2.5 & 0 & 0.75 & 0 & $3 / 40$ & 0 & 50.12 & 44.96 & 7.09 & 0.32 & & & & \\
\hline 18 & 50 & 0 & 2.5 & 0 & 0.75 & 0 & $3 / 40$ & 0 & 48.19 & 46.17 & 7.78 & 0.30 & & & & \\
\hline 19 & 50 & 0 & 2.5 & 0 & 0.75 & 0 & $3 / 40$ & 0 & 51.57 & 45.18 & 7.89 & 0.29 & & & & \\
\hline 20 & 50 & 0 & 2.5 & 0 & 0.75 & 0 & $3 / 40$ & 0 & 48.19 & 44.63 & 8.20 & 0.30 & & & & \\
\hline
\end{tabular}

${ }^{a}$ Independent variables and coded values; $X_{1}$, coded values of temperature; $X_{2}$, coded values of time; $X_{3}$, coded values of KOH concentration; $X_{4}$, coded values of coal-to-alkali ratio

$$
\begin{aligned}
& +b_{34} X_{3} X_{4}+b_{123} X_{1} X_{2} X_{3}+b_{124} X_{1} X_{2} X_{4} \\
& +b_{134} X_{1} X_{3} X_{4}+b_{234} X_{2} X_{3} X_{4}+b_{1234} X_{1} X_{2} X_{3} X_{4}
\end{aligned}
$$

where $y$ is the response (humic acid content), and $X_{\mathrm{i}}$ are coded values of the independent variables $\left(X_{1}\right.$, temperature; $X_{2}$, time; $X_{3}, \mathrm{KOH}$ concentration; $X_{4}$, coal-to-alkali ratio). In the equations given subsequently, only coefficients determined with statistical significance $>95 \%$ will be considered.

The equations obtained using $\mathrm{N}_{2}$ were:

Coal A \%HA $=19.70+15.01 X_{1}+1.79 X_{2}$

Coal P \%HA $=43.13+5.77 X_{1}-2.15 X_{3}$

$$
\begin{aligned}
\text { Coal E \% } \mathrm{HA}= & 7.90+0.57 X_{1}-0.96 X_{3} \\
\text { Coal B \% HA= } & 0.30+0.21 X_{1}+0.02 X_{2}+0.01 X_{3} \\
& -0.04 X_{4}+0.01 X_{1} X_{2}+0.01 X_{1} X_{3} \\
& -0.03 X_{1} X_{4}+0.01 X_{2} X_{3}
\end{aligned}
$$

The results indicate that temperature is the main factor in the extraction of HA, with a direct and definite effect. The alkali concentration had a slight or negative influence on the HA extraction, depending on the rank of the coal. Time and coal-to-alkali ratio did not show a significant effect on the \% HA.

The oxidation process was analysed using the values 
obtained with $\mathrm{N}_{2}$ as blanks for the experiments with air. In this way, the valuees obtained only reflect the nett effect of oxidation on the \% RHA. The equations obtained for the coals investigated, reveal that in general there are a number of significant coefficients, which makes it difficult to obtain their true chemical meaning. Therefore, the results will be discussed using data in Table 1, and the effect of the principal variables will be calculated from Table 1 as the difference between the averages of the results at each level.

Temperature and time directly affect the RHA yields from coals $P$ and $E$. The effect of alkali concentration depends on the coal used. The coal-to-alkali ratio negatively affects coals $A, P$ and $B$. This could be explained by assuming that RHA can undergo further oxidation in a concentration-dependent way. In that case, a lower coal-to-alkali ratio would lead to a lower concentration of RH $\Lambda$ and less extensive degradation.

The results clearly show that there is no systematic behaviour in either process. Subbituminous coals are practically unaffected by the extraction or oxidation processes, as expected considering the high degree of condensation of the organic matrix of these coals. Lignites are affected differently by these processes.

The average extraction of $\mathrm{HA}$ from coal $\mathrm{P}$, keeping temperature and alkali concentration constant, shows a small increase with increasing time at room temperature, and a negligible increase at $80^{\circ} \mathrm{C}$. At this second temperature, the amount of $\mathrm{HA}$ extracted should be near its extraction limit, so the process will probably be controlled by diffusion. On the other hand, the negative effect of alkali concentration could be explained by a salting-out effect ${ }^{9}$. The oxidation process produces small increases of the RHA extracted, probably due to low oxidation at room temperature and to oxidation of both the organic matrix and RHA at $80^{\circ} \mathrm{C}$.

Coal $\mathrm{A}$ behaves in a different way during extraction. From Table 1 it is possible to see that HA are not initially present at high concentrations, but that they are generated by attack of $\mathrm{OH}^{-}$on the organic matrix of coal. This attack, which takes place even in $\mathrm{N}_{2}$ atmosphere and affects polysaccharide-like substances, has been reported by several workers ${ }^{13,14}$ and is favoured by increasing temperature. Alkali concentration also increases the attack, but the salting-out effect opposes the dissolution of the $\mathrm{HA}$ created, thus reducing the extent of degradation. The oxygen from air increases the degradation catalysed by $\mathrm{OH}^{-}$by production of acidic groups, which partially neutralize the excess alkali. This could explain the increase in yield obtained by increasing the alkali concentration. Temperature has a mixed effect on the HA production, because it increases the rate of oxidation of both the organic matrix and RHA. Oxidative degradation can lead to $\mathrm{CO}_{2}$ production, and evolution of $\mathrm{CO}_{2}$ was observed in the acidulation step.

To make comparisons easier, the behaviour of the four coals is shown in Figure 2. The best results obtained for the global process in the factorial designs are always obtained at $80^{\circ} \mathrm{C}, 4 \mathrm{~h}, 0.5 \mathrm{~N} \mathrm{KOH}$ and $1 / 20$ coal-to-alkali $(w: v)$ ratio. These conditions were used for further study of the process.

\section{Characteristics of the oxidized products}

Careful matter balances were performed for all the coals, using the analyses shown in Table 2. The mass variations of weight, weight of HA extracted, carbon, hydrogen, nitrogen, total sulphur and oxygen, calculated for an initial weight of coal sample (daf) of $100 \mathrm{~g}$, are shown in Figure 3. The addition of variations due to each element $(\mathrm{C}, \mathrm{H}, \mathrm{N}, \mathrm{S}, \mathrm{O})$ accounts for the total variation in weight of the sample. When stopping the reaction by acidulation, the most oxidized organic matter will be soluble in acid media, and so will be lost in the filtrate, thus affecting the balances of matter.

There is a loss of weight $(\delta \mathrm{w})$ for all the coals, which varies inversely with the rank. This loss of weight is due to the acid-soluble materials and is indicalive of the ease of the degradation of coals. A more detailed explanation can be given by considering the individual matter balance for every element.

Carbon $(\delta C)$ and Hydrogen $(\delta H)$. The losses of carbon and hydrogen are similar for the studied coals. The $\mathrm{H} / \mathrm{C}$ ratios of the oxidized samples arc higher than those of the original coals, suggesting a predominant aromatic nature for the lost acid-soluble materials. Also, losses of these substances increase with decreasing rank, as expected.

Nitrogen $(\delta N)$. There are no appreciable variations in the amount of this element in the studied coals.

Sulphur $(\delta S)$. There is a significant decrease of total sulphur, similar for all the coals.

Oxygen $(\delta O)$. The increase in oxygen is directly related to the rank, and is quite small in the low rank coals. This does not involve a greater oxidation of the highest rank coals, but higher losses of acid-soluble materials for the lower rank coals. Obviously, these substances will be richer in oxygen-containing functional groups than the organic matrix of the coals.

The RHA increase ( $\delta$ HA) decreases with increasing rank, and is quite small for the higher rank coals. The $\delta \mathrm{HA}$ is inversely related to the global oxygen incorporation. Subbituminous coals that present the highest increase in oxygen content do not yield significant increments of RHA, probably due to low breaking of the coal matrix, leading to large molecular fragments insoluble in acid media, and therefore small losses. Despite the low global oxygen incorporation in low rank coals, their high initial degree of oxidation allows an easy degradation with enough breaking of the core matrix to produce a significant increment of the RHA content. This shows that the limiting factor for the production of RHA is the ease of coal degradation.

Additional information can be obtained by studying the distribution of the main oxygen-containing functional groups, as these are resonsible for the solubility of HA

Table 2 Analyses of the oxidized coals

\begin{tabular}{lrrrr}
\hline & Coal A & Coal P & Coal E & Coal B \\
\hline Weight $^{a}$ (daf) & 7.38 & 5.37 & 6.94 & 8.25 \\
HA (\% daf) & 75.90 & 75.44 & 13.64 & 1.07 \\
$\mathrm{C}(\%$ daf) & 57.12 & 55.08 & 65.03 & 66.87 \\
$\mathbf{H}(\%$ daf) & 4.47 & 5.37 & 4.26 & 4.53 \\
$\mathrm{~N}(\%$ daf) & 0.73 & 0.84 & 0.83 & 1.43 \\
So (\% daf) & 6.62 & 2.95 & 1.39 & 5.20 \\
$\mathrm{O}_{\text {diff }}(\%$ daf) & 31.06 & 35.76 & 27.23 & 21.97 \\
\hline
\end{tabular}

${ }^{a}$ Initial weight of coal $=10 \mathrm{~g}$ 


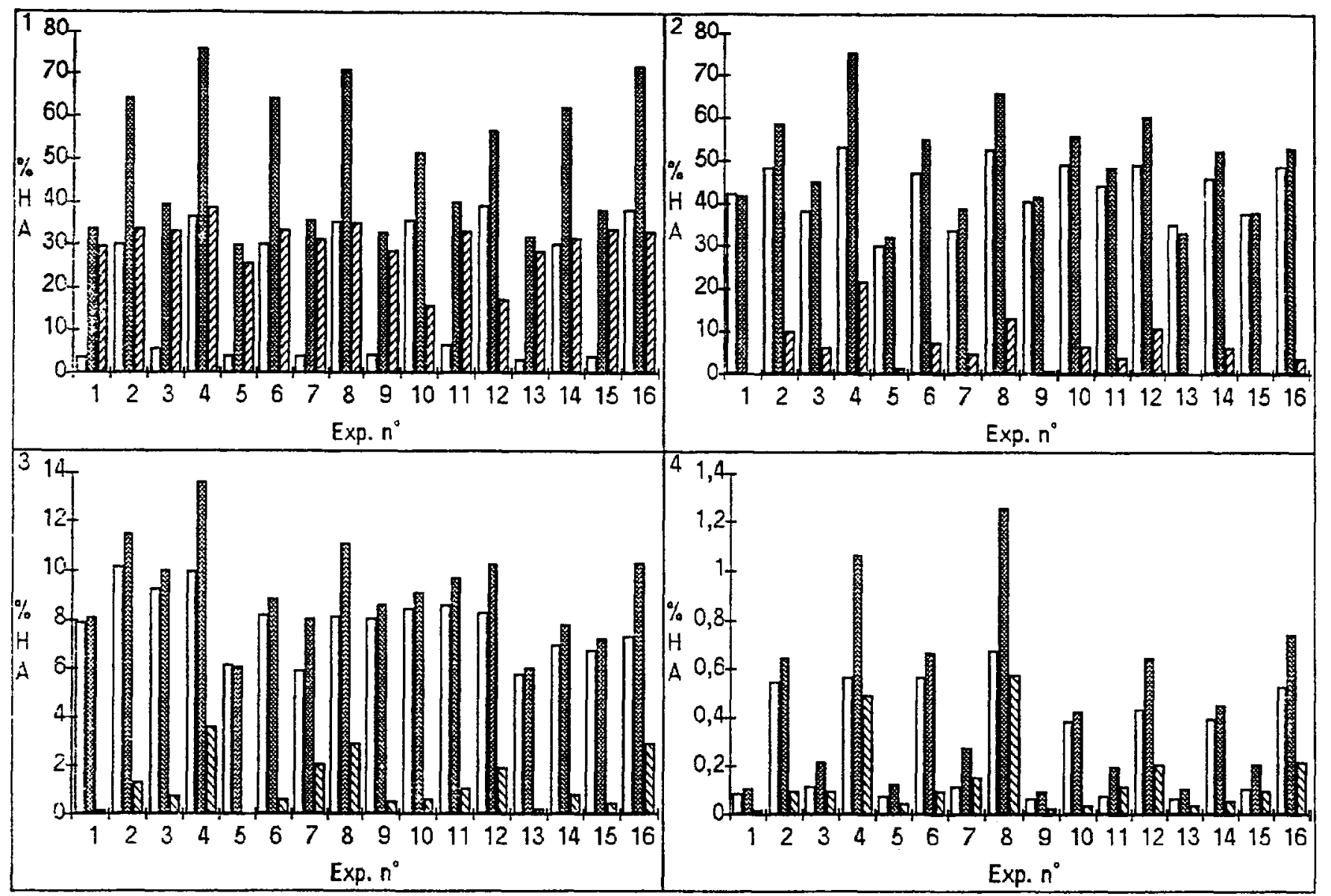

Figure 2 Yield of HA or RHA obtained using air and nitrogen, and net oxidation (by difference): 1, coal A; 2, coal P; 3, coal E; 4, coal B. $\square$, inert; 圈, air; nett oxidation

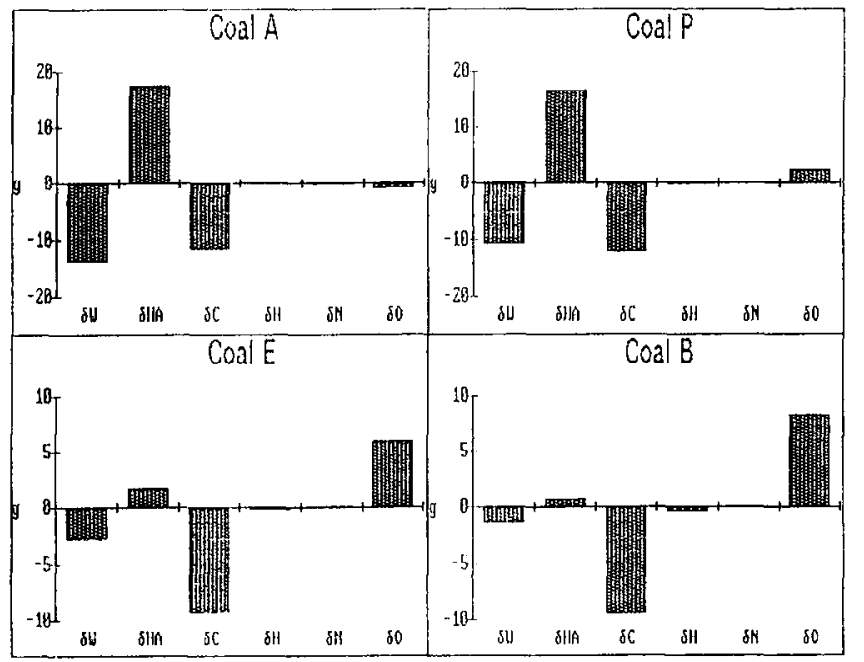

Figure 3 Variation of weight, weight of RHA extracted, and elemental composition, calculated for $100 \mathrm{~g}$ of coal sample (daf)

in aqueous media. Values for the studied samples are presented in Table 3. Carboxyl groups increased during the oxidation, this increment being slightly higher for the subbituminous coals. On the other hand, phenolic groups showed a strong decrease for the low rank coals, a small onc for coal $\mathrm{E}$ and a slight increment for coal $\mathrm{B}$. This reflects the production of oxygen-containing functional groups by oxidation, and probably saponification of phenolic esters, together with the loss of acid-soluble material. The losses for the low rank coals, determined by visual inspection, are higher than those for the
Table 3 Evolution of the main oxygen-containing functional groups

\begin{tabular}{llccccc} 
& \multicolumn{6}{c}{ Acidity } \\
\cline { 2 - 7 } Coals & Total $^{a}$ & $\delta \mathrm{meq}^{b}$ & $\mathrm{COOH}$ & $\delta \mathrm{meq}^{b}$ & Phenol & $\delta \mathrm{meq}^{b}$ \\
\hline $\mathrm{A}$ & 6.84 & & 3.10 & & 3.75 & \\
$\mathrm{~A}_{\text {oxid }}$ & 6.83 & -0.92 & 4.36 & 0.69 & 2.47 & -1.60 \\
$\mathrm{P}$ & 7.48 & & 2.15 & & 5.33 & \\
$\mathrm{P}_{\text {oxid }}$ & 6.40 & -1.76 & 2.90 & 0.44 & 3.49 & -2.21 \\
$\mathrm{E}$ & 4.77 & & 0.61 & & 4.16 & \\
$\mathrm{E}_{\text {oxid }}$ & 5.51 & 0.57 & 1.62 & 0.96 & 3.89 & -0.39 \\
$\mathrm{~B}$ & 1.43 & & 0.06 & & 1.37 & \\
$\mathrm{~B}_{\text {oxid }}$ & 2.81 & 1.34 & 0.90 & 0.83 & 1.91 & 0.51 \\
\hline
\end{tabular}

${ }^{a}$ Values of acidity expressed in meq/g

${ }^{\circ} \delta$ meq calculated for $1 \mathrm{~g}$ of coal

subbituminous coals, producing a lower increase of $\mathrm{COOH}$ groups and a considerable decrease of phenolic $\mathrm{OH}$. This cannot completely explain the values obtained for coals $P$ and $E$, which show an increase in oxygen content that is not wholly reflected in the acidic functional groups, suggesting the formation of oxygen-containing, but non-acidic, functional groups.

The overall results obtained, and the demands of the oxidation process, indicate that the method is only worthwhile for coals like coal A, which do not show a high initial content of HA but whose organic matrices are susceptible to the necessary transformations under the mild conditions used.

As alkaline oxidation in severe conditions has been proposed as a method for reducing the sulphur content 
Table 4 Evolution of sulphur forms ${ }^{a}$

\begin{tabular}{|c|c|c|c|c|c|c|c|c|}
\hline Coals & $\% \mathrm{St}$ & \%lost & $\% \mathrm{Sp}$ & $\%$ lost & $\% \mathrm{Ss}$ & $\%$ lost & $\%$ So & $\%$ lost \\
\hline A & 6.89 & & 0.88 & & 0.00 & & 6.01 & \\
\hline$A_{\text {oxid }}$ & 6.46 & 20.26 & 0.00 & 100.00 & 0.00 & - & 6.35 & 10.13 \\
\hline $\mathrm{P}$ & 4.81 & & 2.06 & & 0.58 & & 2.17 & \\
\hline $\mathrm{P}_{\text {oxid }}$ & 3.55 & 34.88 & 1.53 & 33.16 & 0.00 & 100.00 & 1.90 & 21.00 \\
\hline $\mathbf{E}$ & 4.02 & & 1.96 & & 0.45 & & 1.61 & \\
\hline$E_{\text {oxid }}$ & 2.71 & 36.66 & 1.48 & 31.55 & 0.00 & 100.00 & 1.12 & 34.90 \\
\hline B & 7.01 & & 1.76 & & 0.67 & & 4.58 & \\
\hline$B_{\text {oxid }}$ & 6.06 & 19.97 & 0.99 & 48.19 & 0.00 & 100.00 & 4.93 & 0.46 \\
\hline
\end{tabular}

${ }^{a}$ Dry basis

of coals ${ }^{15,16}$, additional analyses of the evolution of sulphur forms in the milder conditions used in this work were performed. Results are shown in Table 5.

Total sulphur decreases by a similar absolute amount for all the coals. This reflects the solubilization of sulphates and their subsequent elimination in the filtrate. Pyritic sulphur also decreases in a rank-independent way, as expected. This decrease is nearly constant and is independent of the total amount of pyritic sulphur in the parent coals. The evolution of organic sulphur is closely related to the chemical nature of the $\mathrm{C}-\mathrm{S}$ bonds. Coal $\mathrm{B}$, the highest rank coal, is likely to have a greater degree of condensation, and so it should be less susceptible to elimination of organic sulphur. Coals with a lower degree of condensation should have a smaller fraction of organic sulphur in aromatic structures, making its elimination easier. However, the $\% \mathrm{~S}_{0}$ in the final products can be higher than in the parent coals, due to losses of weight.

These results show that the mild conditions used are not sufficient for practical use of the method for sulphur removal. Taking into account the losses of weight experienced by the coals studied, more severe conditions will probably lead to the dissolution of most of the coal, especially for low rank coals, so the applicability of this method as a desulphurization process seems doubtful.

\section{REFERENCES}

1 Wender, I., Heredy, L. A., Neuworth, M. B. and Dryden, I. G. C. in 'Chemistry of Coal Utilization', 2nd supplementary volume (Ed. M. A. Elliott), John Wiley and Sons, New York, USA, 1981, chapter 8

2 Yokokawa, C., Watanabe, Y., Kajiyama, S. and Takegami, Y. Fuel 1962, 41, 209

3 Kamiya, Y. Fuel 1963, 41, 347

4 van Krevelen, D. W. in 'Coal', Elsevier, New York, USA, 1961, p. 197

5 Romero, C., Rómez, V., Gavilán, J. M. and Fernández, I. Spanish Patent no. 4387121976

6 Estévez, M., Juan, R., Ruiz, C. and Andrés, J. M. Fuel 1990, 69, 157

7 Moliner, R., Ruiz, C., Uliaque, C. and Gavilán, J. M. Fuel 1983 , 62, 1369

8 Umarov, T. Zh. et al. Khim. Tverd. Topl. 1987, 14, 42

9 Grigor'eva, E. A. and Kukharenko, T. A. Khim. Tverd. Topl. $1969,5,28$

10 Kapo, G. and Calvert, S. Ind. Eng. Chem., Proc. Des. Dev. 1966, 5,97

11 Schafer, H. N. S. Fuel $1970,49,197$

12 Sshafer, H. N. S. Fuel 1970, 49, 271

13 Swift, R. S. and Posner, A. M. J. Soil Sci. 1972, 23, 381

14 Davis, H. and Mott, C. J. B. J. Soil Sci. 1981, 32, 393

15 Morrison, G. F. in 'Chemical Desulphurisation of Coal', Report number ICTIS/TR15, IEA Coal Research, London, UK, 1981

16 Eliot, R. C. in 'Coal Desulfurization prior to Combustion', Noyes Data Corp., New Jersey, USA, 1978 